\title{
Discourse Connectives in L1 and L2 Argumentative Writing
}

\author{
Chunyu $\mathrm{Hu}^{1} \&$ Yuanyuan $\mathrm{Li}^{1}$ \\ ${ }^{1}$ School of English for International Business, Guangdong University of Foreign Studies, China \\ Correspondence: Chunyu Hu, School of English for International Business, Guangdong University of Foreign \\ Studies, Guangzhou, 510420, China. Tel: 86-203-631-7183. E-mail: gwhcy@gdufs.edu.cn
}

Received: March 8, 2015

Accepted: March 26, 2015

Online Published: July 21, 2015

doi:10.5539/hes.v5n4p30

URL: http://dx.doi.org/10.5539/hes.v5n4p30

\begin{abstract}
Discourse connectives (DCs) are multi-functional devices used to connect discourse segments and fulfill interpersonal levels of discourse. This study investigates the use of selected 80 DCs within 11 categories in the argumentative essays produced by L1 and L2 university students. The analysis is based on the International Corpus Network of Asian Learners of English (ICNALE) which consists of essays written by native speakers (NS) and non-native speakers (NNS) from 10 countries and regions in Asia. WordSmith Tools were used to generate the quantitative profile of the DCs, while follow-up qualitative analysis in the context of usage provided additional interpretive insights. The total frequency of DCs used by Hong Kong and Singaporean students is significantly less than do L1 writers, mainly because the addictive and is by far less frequent in the essays produced by L2 writers. Hong Kong students use much more enumerating, resultive and summative DCs than both L1 writers and L2 writers from Thailand and Singapore. Thai students, on the other hand, employ the causal device because much more than both L1 and other L2 writers. Hong Kong and Singaporean students are more formal in tone than L1 and Thai students when using the adversative and resultive DCs. Despite the apparent differences, there are considerable similarities of usage, with and, but, because, so, however and therefore occurring among the top 10 most frequently used devices of both L1 and L2 writers, although with strikingly different frequencies. These findings shed light on the pragmatic uses of DCs by L1 and L2 writers as a way to influence the interpretation of the message, and thus succeed in achieving their communicative intentions.
\end{abstract}

Keywords: discourse connectives, relevance theory, argumentative writing, learner corpus research

\section{Introduction}

Discourse connectives (henceforth DCs) have been the subject of intensive investigation over the past three decades, which "is likely due to their complex nature, reflected in key theoretical issues involving semantic vs. pragmatic meaning, propositional vs. non-propositional meaning and procedural vs. conceptual meaning" (Camiciottoli, 2010, p. 650). Its complex nature lead to various research perspectives which in turn result in many other terms similar to DCs, among which are sentence connectives (Halliday \& Hasan, 1976), pragmatic connectives (Van Dijk, 1979), logical connectives (Hyland, 1998), pragmatic markers (Brinton, 1996; Andersen, 2001; Aijmer \& Simon-Vandenbergen, 2006; Aijmer, 2013), discourse markers (Schiffrin, 1987; Jucker \& Ziv, 1998; Blakemore, 2002; Fraser, 2006), discourse operators (Redeker, 1991), discourse particles (Fischer, 2006), linking adverbials (Biber et al., 1999), and adverbial connectors (Altenberg, 2006). Of all the terms the most popular ones are discourse markers, pragmatic markers, and discourse connectives. Considering that discourse markers and pragmatic markers are "particularly characteristic of spoken dialogue" (Biber et al., 1999, p. 140), we will use the term discourse connectives in that they are well suited to this study since this paper focuses exclusively on elements that have a connecting function in written discourse.

As an indispensable component in language, DCs fulfill important functions on the textual and interpersonal levels of discourse. It seems that the primary function of DCs is to state the speaker/writer's perception of the relationship between two units of discourse. Because DCs explicitly signal the connections between passages of text (by way of addition, enumeration, summation, apposition, result/inference, contrast/concession, and transition), they are important devices for creating textual cohesion (Biber et al., 1999, p. 875). From this perspective, they can be seen as metadiscursive items that function on the textual level (Hyland, 1998, 2005). However, DCs also express interpersonal meaning by not only drawing the listener's/reader's attention to the particular type of connection that exists, but also suggesting how the speaker/writer intends for it to be construed (Redeker, 1991; Barton, 1995). In other words, DCs “indicate the speaker's perception as to how the inferential 
processes required for the interpretation should proceed" (Andersen, 2001, p. 79). This serves to constrain the hearer's cognitive interpretive context, thereby reducing the processing effort and contributing to the relevance of the proposition. Among the many functions that DCs may fulfill in different domains, there are "the sequential structure of the dialogue, the turn-taking system, speech management, interpersonal management, the topic structure, and participation frameworks" (Fischer, 2006, p. 9).

Writing is a dynamic process of linguistic encoding. From the pragmatic-cognitive perspective, what is encoded in writing included not only the conceptual meaning that reflects the central idea of the written discourse but also the procedural meaning that facilitates the comprehension of the discourse. Considering that writers generally use discourse connectives to encode the procedural meaning, it is worthwhile to investigate how L1 and L2 university students make use of DCs in their argumentative writing. Since studies on DCs in L2 argumentative essays are normally approached from either the coherence theory or the relevance theory, the next section will first compare and contrast the two theoretical perspectives, and then review L2 research on DCs.

\section{Literature Review}

\subsection{Two Theoretical Perspectives on Discourse Connectives}

Coherence theory and relevance theory are two basic frameworks which look at DCs over the past decades. The main argument of coherence theory is quite clear: sentences are linked together coherently, and such coherence is often marked by the use of discourse connectives (Halliday \& Hasan, 1976; Mann \& Thompson, 1988; Sanders et al., 1992; Knott \& Dale, 1994, cited in Zufferey, 2015). Thus (Schourup, 2011, 2010) claims that research on DCs "commonly comes from the assumption that these expressions function primarily to signal relationship between units of discourse and thereby contribute to discourse coherence or textuality".

While the coherence framework focuses more on the textual functions, relevance theory on cognitive processes (Andersen et al., 1999, p. 1339). This point is clearly made by Blakemore that "[t]he object of study is not discourse, but the cognitive processes underlying successful communication, and the expressions which have been labeled discourse markers must be analyzed in terms of their input to those processes" (Blakemore, 2002, $p$. 5). The coherence theory explains well what the function of DCs is in the text, but it fails to explain the reason that hinders the reader's comprehension of the propositional content. In other words, we may know that inappropriate usage of DCs may cause incoherence, but we are not aware of the specific links between incoherence and troubles in reading. Relevance theory may give an answer to that one, as we know the hearer or reader can interpret the sentence in several ways and the optimum choice is achieved through the most relevant one. The incoherence may make the relevance implicit or in a different way, thus causing the difficulties in reading comprehension.

The general idea in relevance theory is that the linguistic form of a sentence or an utterance (i.e. propositional representations) potentially gives rise to a number of possible interpretations. The hearer's task then is to find the most relevant interpretation in the given context (cf. Sperber \& Wilson, 1995). Blakemore claims that DCs are used to indicate how the relevance of one discourse segment is dependent on another, that is, they "impose constraints on relevance by virtue of the inferential connections they express" (Blakemore, 1987, p. 141). DCs guide the hearer in this task by constraining the number of possible interpretations, and thus they "encode instructions for processing propositional representations" (Blakemore, 1992, p. 150f.), which Blakemore also terms "encoding procedural meaning". We can categorize different types of DCs based on different contextual effect it brings within the framework of relevance theory.

\subsection{L2 Research on Discourse Connectives in L2 Argumentative Writing}

The study of DCs in L2 writing has always been the intensive subject of coherence studies. A number of studies (e.g. Green, Christopher, \& Jacquelyn, 2000; Liu \& Braine, 2005; Yang \& Sun, 2012), have all examined cohesive devices in ESL/EFL writing. They all found that the quality of essays is somehow related to the number of cohesive devices in a text.

Within the framework proposed by Halliday and Hasan (1976), Yang and Sun (2012) collected essays written by 60 university students of different proficiency levels, seniors and sophomores respectively and they discovered that there was no significant difference in the use of all subcategories of conjunction except adversity between seniors and sophomores. The frequency of conjunctions in a text is noticeably positively related with the quality among seniors' essays, but not in sophomores'. A similar finding has been further confirmed in Liu and Braine's study. In Liu and Braine's (2005) study, they collected all together 50 argumentative essays and found that the quality of writing was positively correlated with the number of conjunctions and the total number of cohesive devices used. 
L2 research on DCs from the perspective of relevance theory focuses more on the cognitive process. As we know the hearer or reader can interpret the sentence in several ways and the optimum choice is achieved through the most relevant one. The incoherence may make the relevance implicit or in a different way, thus causing the difficulties in reading comprehension. Naturally, knowledge of DCs has been considered an indispensable part of one's writing skills. It concerns one's ability to use a wide range of conversational routines and discourse strategies in managing one's interactions with others and to use language in "culturally, socially and situationally appropriate ways" (Celce-Murcia \& Olshtain, 2000, p. 433, cited in Wei 2011). A number of studies have focused on the development of writing skills for L2 students and chose DCs as an index for it to compare its usages in the essays written by groups of different levels of English proficiency or a diachronic study focusing on groups of the same level of English proficiency.

Chen (2002) explores the usage of DCs in argumentative writings written by graduates in consecutive 3 years. Building on Blakemore's $(1987,1992)$ account, Chen (2002) classified 36 DCs into 3 types and 16 sub-types on the basis of three contextual effects, believing that we can achieve these contextual effects by using different DCs. He finds out that the total frequency varies little in 3 years. Among the 3 types he classifies, all of the graduates used the first type more than the other two. In using DCs to connect two propositions, students used more additive, contrastive and conclusive ones. Lu (2012), based on Chen's (2002) study, revealed that the total frequency of DCs and frequency of each type increases with English levels. Compared with different subtypes of DCs, sophomores use more DCs than freshmen except listing, concessive and exemplifying markers. There also exist some problems in using DCs in argumentative essays among Chinese students majoring in English, such as overuse, underuse, misuse and mechanical uses.

Among the various account for L2 use of DCs, it is claimed that L2 writing is strongly influenced by the writer's L1 (Crossley et al., 2011). Granger and Tyson (1996, p. 22), for example, attributes the overuse of corroborative connectives such as in fact, indeed and actually in English by native French speakers to the frequent use of the connective en effet in French. But Tapper (2005, cited in Zufferey et al., 2015, p. 3) notes that a similar overuse is found in texts from Swedish native speakers, and concludes that this phenomenon could be a "shared learner language feature". It is clear that L2 research of DCs that examines data from one source of language may jump to some wrong conclusions. In order to avoid this pitfall, we may need to conduct research based on a variety of language backgrounds.

Another problem of previous studies is that the essay topics are not well controlled, which makes it somewhat ambiguous as to whether the observed linguistic discrepancies are caused by the L1/L2 difference or by the topic differences. Moreover, existing work on DCs is primarily based on random or unspecified selections of individual terms with no clear indication of the representativeness of the items under study. Given these observations, this study aims to overcome the problems facing previous research by using more comparable data and by a more careful selection of DCs.

\section{Method}

\subsection{Research Questions}

This study sets out to investigate how L1 and L2 university students use DCs in their argumentative essays to achieve textual and interpersonal functions. More specifically, it aims to address the following two questions:

RQ1: In which aspects do L2 writers differ from their L1 counterparts in the use of DCs when writing argumentative essays of the same topics?

RQ2: In which aspects do L2 writers of different L1 grounds differ from each other in the use of DCs when writing argumentative essays of the same topics?

\subsection{Data}

The data come from the written component of the International Corpus Network of Asian Learners of English (ICNALE), which consists of 1.3 million words of 5600 essays written by 2600 college students in 10 Asian countries and areas as well as 200 English Native Speakers (Ishikawa, 2013). The ICNALE is a new learner corpus designed for a reliable contrastive IL analysis of varied English learners in Asia. The conditions for writing (topics, time, length, etc.) are strictly controlled, which guarantee a high comparability of data, allowing us to observe a more reliable comparison of the range and frequency of DCs among groups under investigation. The essays are of argumentative mode with two set topics:

Topic 1: Is it important for college students to have a part time job?

Topic 2: Should smoking be completely banned at all the restaurants in the country? 
For the EFL participants, based on their scores in the standard L2 proficiency tests such as TOEIC or TOEFL or in the standard vocabulary size test (VST), their proficiencies were classified into four levels: A2 (Waystage), B1_1 (Threshold: Lower), B1_2 (Threshold: Upper), and B2+ (Vantage or higher). Table 1 presents basic statistics of the sub-corpora chosen by this study.

Table 1. Basic statistics in NS and NNS groups

\begin{tabular}{lllll}
\hline & HKG_B1_2 & SIN_B1_2 & THA_B1_2 & ENS1 \\
\hline Numbers of participants & 52 & 100 & 100 & 100 \\
Numbers of essays & 104 & 200 & 200 & 200 \\
Tokens in corpus & 24509 & 48564 & 45393 & 44694 \\
Types in corpus & 2512 & 3943 & 2934 & 3393 \\
Types/token ratio & 10.25 & 8.12 & 6.46 & 7.59 \\
Average sentence length & 17.25 & 21.44 & 16.59 & 24.44 \\
std.dev. & 8.25 & 9.97 & 11.92 & 11.53 \\
\hline
\end{tabular}

\subsection{The Analytical Approach}

The analysis of L1 and L2 essays combined quantitative and qualitative techniques. The first step is to specify the exact criteria in choosing DCs. Among the scholars, there are still debates over some specific items.

In order to find the appropriate DCs for study, we made a pre-compiled list based on previous studies (Biber et al., 1999; Blakemore, 1987, 1992; Chen, 2002; Hyland, 1998, 2005; Schourup, 1999, 2011) and have chosen 80 DCs under investigation. The 80 DCs were then be clssified into three types based on the contextual effect within the framework of relevance theory proposed by Sperber and Wilson (1995) and further into 11 sub-types, as shown in Table 2.

Table 2. The DCs and classification used in this study

\begin{tabular}{|c|c|c|}
\hline Contextual & Semantic Categories & Discourse Connectives \\
\hline \multirow{3}{*}{$\begin{array}{l}\text { Type I: } \\
\text { strengthening } \\
\text { an assumption }\end{array}$} & Additive & $\begin{array}{l}\text { and, also, in addition, besides, further(more), moreover, } \\
\text { likewise, by the same token }\end{array}$ \\
\hline & Enumerating & $\begin{array}{l}\text { next, first(ly), second(ly), third(ly), finally, for one thing, for } \\
\text { another, in the first/second place, first of all, to begin with }\end{array}$ \\
\hline & Apposition & $\begin{array}{l}\text { namely, that is, I mean, in other words, similarly, in the same } \\
\text { way, for instance, for example, which is to say, i.e, specifically }\end{array}$ \\
\hline \multirow{5}{*}{$\begin{array}{l}\text { Type II: } \\
\text { contradicting } \\
\text { an assumption }\end{array}$} & Adversative & but, yet, however, nevertheless, despite that, in spite of that \\
\hline & Concessive & $\begin{array}{l}\text { anyhow, anyway, in any case, at any rate, after all, although, } \\
\text { though }\end{array}$ \\
\hline & Alternative & or, alternatively \\
\hline & Corroborative & as a matter of fact, instead, rather, in fact, actually \\
\hline & Contrastive & $\begin{array}{l}\text { on the other hand, by contrast, in contrast, conversely, instead, } \\
\text { on the contrary, by comparison, alternatively }\end{array}$ \\
\hline \multirow{3}{*}{$\begin{array}{l}\text { Type III: } \\
\text { making } \\
\text { contextual } \\
\text { implication }\end{array}$} & Causal & because of this, for this reason, on account of this, because \\
\hline & Resultive & $\begin{array}{l}\text { so, then, thus, hence, therefore, as a result, consequently, in } \\
\text { consequence }\end{array}$ \\
\hline & Summation & $\begin{array}{l}\text { to sum up, in conclusion, to conclude, in short, in a word, all in } \\
\text { all, overall, to summarize, in brief, in sum, briefly, in a nutshell }\end{array}$ \\
\hline
\end{tabular}


Selected DCs were then processed with the concordancer of Wordsmith Tools 5.0 (Scott, 2008) to obtain frequency data and to identify interesting trends for follow-up qualitative analysis. The concordance output was then subjected to a qualitative analysis in order to isolate true DCs from unwanted items. For example, we may find a lot concordance lines that contains the DCs, but not serve the function of DCs, as shown by examples of (1)-(6).

(1) First and foremost, smoking does harm both to the smoker himself and people in the neighborhood. (HKG_SMK_019_B1_2)

(2) Japan has a lot of food that is well known for its distinctiveness, foods such as sushi, tempura, sukiyaki, okonomiyaki and so on... (ENS_SMK_085_XX_0)

(3) In this way, I was able to both further my career prospects while retaining focus on my studies. (ENS_PTJ_007_XX_0)

(4) Governments should place a ban on employers who employ people who are still in further education. (ENS_PTJ_099_XX_0)

(5) Smoking is directly related to cancer, and the number of deaths each year as a result of tobacco use is nothing less than staggering. (ENS_SMK_078_XX_0)

(6) Smoking is a highly addictive habit, and perhaps if the restaurants ban it, the overall health of the country will improve. (ENS_SMK_006_XX_0)

\section{Results and Discussion}

\subsection{Quantitative Analysis}

As shown in Table 3, while there is no significant difference in the overall frequencies between Thai students and L1 students, Hong Kong and Singaporean students underuse DCs than do their L1 counterparts.

Table 3. Total DCs used by L1 and L2 writers (per 50,000 words)

\begin{tabular}{lllcl}
\hline & HKG B1_2 & SIN_B1_2 & THA_B1_2 & ENS1 \\
\hline Total DCs & $1155^{* *}$ & $1100^{* *}$ & 1422 & 1350 \\
\hline
\end{tabular}

Notes. (1) this study adopts the log-likelihood ratio test to check whether the difference in L1 and L2 students' frequency of a certain category/device is statistically significant, which is more precise than chi-square test; (2) * signifies the existence of striking difference $(\mathrm{p}<0.05$, log-likelihood ration is greater or equal to 3.84$)$, ** signifies the existence of highly significant difference $(\mathrm{p}<0.01$, log-likelihood ratio is no less than 6.63$)$.

Table 4 lists the most frequently used DCs by L1 and L2 writers. It is clear that there are considerable similarities of usage, with and, but, because, so, however and therefore occurring among the top 10 most frequently used devices of both L1 and L2 writers, although with strikingly different frequencies. The greatest difference is and (nearly three times more often in L1 sample than in L2 sample by Hong Kong and Singaporean students).

Table 4. The top ten DCs used by L1 and L2 writers

\begin{tabular}{lllllllll}
\hline & HKG_B1_2 & & SIN_B1_2 & & THA_B1_2 & ENS1 \\
\hline Rank & DCs & Freq. & DCs & Freq. & DCs & Freq. & DCs & Freq. \\
1 & and & 190 & and & 176 & because & 314 & and & 494 \\
2 & therefore & 104 & however & 129 & and & 282 & but & 178 \\
3 & so & 98 & because & 108 & but & 223 & because & 163 \\
4 & however & 98 & hence & 59 & so & 210 & so & 149 \\
5 & because & 96 & therefore & 55 & however & 44 & however & 48 \\
6 & but & 76 & but & 49 & moreover & 35 & also & 47 \\
7 & also & 47 & also & 42 & or & 35 & therefore & 40 \\
8 & first(ly) & 35 & or & 40 & then & 35 & then & 22 \\
9 & as a result & 29 & thus & 40 & finally & 26 & next & 22 \\
10 & thus & 29 & further(more) & 39 & therefore & 26 & for example & 21 \\
Total & & 800 & & 737 & & 1230 & & 1184 \\
\hline
\end{tabular}


Interestingly, the ten most frequently used items account for $88 \%$ of the total in L1 essays and $86 \%$ in L2 essays written by Thai students, but only $71 \%$ and $67 \%$ of the total in L2 essays written by Hong Kong and Singaporean students, indicating that overall the L1 essays contain a more restricted range of DCs than those written by two L2 groups.

It is useful to categorize the items into semantic/pragmatic classes for comparison. Table 5 shows that there exist considerable differences in Type I-III and sub-types between L1 and each L2 group and within three L2 groups. Of 11 sub-types, the three groups of L2 all underuse the additive subtype compared with NS, resulting in an underuse in the first type. Also, they overuse the corroborative subtype. Except this, there seems to be not much common features shared by the three groups of L2. It is also clear that DCs of some categories (such as causal and summation) are more frequently used by Hong Kong and Singaporean students but by Thai students.

Table 5. Semantic categorizes of DCs in the essays of L1 and L2 essay (per 50,000 words)

\begin{tabular}{llllll}
\hline Types & Semantic Categories & HKG_B1_2 & SIN_B1_2 & THA_B1_2 & ENS1 \\
\hline \multirow{5}{*}{ Type I } & Additive & $324^{* *}$ & $319^{* *}$ & $359^{* *}$ & 562 \\
& Enumerating & $108^{* *}$ & 62 & $99^{* *}$ & 65 \\
& Apposition & 20 & 45 & 18 & 31 \\
& Total & $452^{* *}$ & $426^{* *}$ & $463^{* *}$ & 656 \\
& Adversative & $178^{* *}$ & 201 & 269 & 230 \\
\multirow{2}{*}{ Type II } & Concessive & 10 & 18 & 4 & 9 \\
& Clternative & 16 & $40^{* *}$ & $35^{* *}$ & 13 \\
& Corroborative & $12^{*}$ & $37^{* *}$ & $13^{*}$ & 4 \\
& Total & $29 * *$ & 14 & 4 & 9 \\
Type III & Causal & 245 & 310 & 325 & 265 \\
& Resultive & $96 * *$ & $110^{* *}$ & $314^{* *}$ & 166 \\
& Summation & $286^{* *}$ & 218 & $283^{* *}$ & 223 \\
\hline
\end{tabular}

In order to further explore what might be behind the above findings, Table 6-8 list the frequency of each DC (except those that do not occur in both L1 and L2 essays). The DCs (despite that, in spite of that, by the same token, etc) that neither L1 nor L2 writers use occur typically in the academic style (cf. Biber et al., 1999), suggesting that L1 and L2 students have a limited range in using DCs and their argumentative writing are less formal by nature.

Table 6. The first type of DCs in the essays of L1 and L2 writers

\begin{tabular}{|c|c|c|c|c|c|}
\hline Categories & DCs & HKG_B1_2 & SIN_B1_2 & THA_B1_2 & ENS1 \\
\hline \multirow{5}{*}{ Additive } & and & $190 * *$ & $176^{* *}$ & $282 * *$ & 494 \\
\hline & also & 47 & 42 & $4 * *$ & 47 \\
\hline & in addition & 14 & $28 * *$ & 14 & 9 \\
\hline & besides & $24 * *$ & $13 * *$ & $11 * *$ & 1 \\
\hline & further(more) & $27 * *$ & $39 * *$ & 12 & 11 \\
\hline \multirow{7}{*}{ Enumerating } & moreover & $22 * *$ & $21 * *$ & $35 * *$ & 0 \\
\hline & next & $0 * *$ & $2 * *$ & $2 * *$ & 22 \\
\hline & first(ly) & $35^{*}$ & $36^{* *}$ & 24 & 17 \\
\hline & second(ly) & 24 & 19 & 24 & 15 \\
\hline & third(ly) & 4 & 5 & 14 & 8 \\
\hline & finally & $8^{*}$ & $0 * *$ & 25 & 21 \\
\hline & for one thing, & 0 & 0 & 1 & 0 \\
\hline
\end{tabular}




\begin{tabular}{llllll}
\hline & for another & 2 & 0 & 0 & 0 \\
in the first place & 2 & 0 & 0 & 7 & 3 \\
first of all & $24^{*}$ & 0 & 0 & 0 \\
to begin with & $8^{* *}$ & 0 & 0 & 3 \\
that is & 2 & 1 & 1 & 1 \\
& I mean & 0 & 2 & 0 & 0 \\
& in other words & 2 & 1 & 0 & 0 \\
& similarly & 0 & 2 & 0 & 2 \\
& in the same way & 0 & 1 & 1 & 21 \\
\hline
\end{tabular}

Table 7. The second type of DCs in the essays of L1 and L2 writers

\begin{tabular}{llllll}
\hline Categories & DCs & HKN_B1_2 & SIN_B1_2 & THA_B1_2 & ENS1 \\
\hline \multirow{5}{*}{ Adversative } & but & $76^{* *}$ & $49^{* *}$ & $223^{*}$ & 178 \\
& yet & 4 & $13^{* *}$ & 0 & 3 \\
& however & $98^{* *}$ & $129^{* *}$ & 44 & 48 \\
& nevertheless & 0 & $9^{* *}$ & 1 & 1 \\
Concessive & anyway & 0 & 0 & 2 & 1 \\
& after all & 2 & $8^{*}$ & 1 & 1 \\
& though & 8 & 9 & $1 *$ & 7 \\
Clternative & or & 16 & $40^{* *}$ & $35^{* *}$ & 13 \\
& instead & 4 & $8^{* *}$ & 2 & 0 \\
& rather & 0 & 2 & 0 & 1 \\
\multirow{3}{*}{ Contrastive } & in fact & 8 & $14^{* *}$ & 7 & 2 \\
& actually & 0 & $12^{* *}$ & 4 & 8 \\
& on the other hand & $20^{*}$ & 13 & 4 & 0 \\
& in contrast & 2 & 1 & 0 & 1 \\
& conversely & 0 & 0 & 0 & 0 \\
\hline
\end{tabular}

Table 8. The third type of DCs in the essays of L1 and L2 writers

\begin{tabular}{llllll}
\hline Categories & DCs & HGN_B1_2 & SIN_B1_2 & THA_B1_2 & ENS1 \\
\hline \multirow{3}{*}{ Casual } & because of this & 0 & 1 & 0 & 1 \\
& for this reason & 0 & 1 & 0 & 1 \\
& because & $96^{* *}$ & $108^{* *}$ & $314^{* *}$ & 163 \\
& so & $98^{* *}$ & $33^{* *}$ & $210^{* *}$ & 149 \\
& then & $8^{* *}$ & 26 & 35 & 22 \\
& thus & $29^{* *}$ & $40^{* *}$ & 7 & 2 \\
& hence & $18^{* *}$ & $59^{* *}$ & 0 & 0 \\
& therefore & $104^{* *}$ & 55 & 26 & 40 \\
& as a result & $29^{* *}$ & 6 & 4 & 7 \\
& consequently & 0 & 0 & 0 & 2 \\
& to sum up & $4^{*}$ & 1 & $7 * *$ & 0 \\
\hline
\end{tabular}




\begin{tabular}{lllll}
\hline to conclude & $27^{* *}$ & 0 & 2 & 0 \\
in short & $4^{*}$ & 0 & 1 & 0 \\
all in all & $18^{* *}$ & 3 & 2 & 3 \\
overall & 0 & 4 & 0 & 2 \\
in sum & 0 & 1 & 0 & 0 \\
in a nutshell & 2 & 2 & 0 & 0 \\
\hline
\end{tabular}

The detailed comparison presented in Table 6-8 reveals that L2 writers have the general tendency to overuse more DCs than underuse them. This observation is especially true of Hong Kong students who overuse 17 items but only underuse 7 ones among the 57 DCs listed in the above tables.

\subsection{Qualitative Analysis}

To shed more light on the role of the DCs across the four sub-corpora, the follow-up qualitative analysis was carried out on the most frequent DCs used by L1 or L2 writers.

\subsubsection{The Addictive DCs}

While the addictive DCs are most frequently used devices by both L1 and L2 writers, they are also most significant underused devices by all NNS groups compared to their L1 counterparts. The relatively less frequent use of and by L 2 writers is clearly the main reason, as evident in Table 6. The item and alone in L1 essays accounts for $37 \%$ of the total, its high frequency being the primary reason why Hong Kong and Singaporean students underuse the DCs as a whole.

One of the possible reasons is that and actually functions as a multifunctional DC in L1 students' essasys. The concordance lines of and in ENS1 exhibit a clear pattern of and I think/feel/don't think/agree that/this..., which occurs 85 times in ENS1, as demonstrated by (7). This pattern seldom appears in the L2 writes' essays with few exceptions in Thailand students' corpus. In example 7, the former sentence usually forms the reason for the writers' opinions in the coming sentences and and here actually functions as a resultive DC, with a much less strong degree than so. In addition, and can imply other logic relationships, such as additive in example 8 . Unlike this, and used in the L2 corpus mainly indicates an additive relationship, as demonstrated by example 10 and 11 with really few exceptions. Thus, the less function may determine its relatively lower frequency in the L2 corpora.

(7) I have only just entered college, and I think I would like to take a semester or two to get accustomed to the college environment before I tried to do too many things at once. (ENS_PTJ_069_XX_0)

(8) I am a smoker, and I feel that I should have the right to smoke anywhere I want to. (ENS_SMK_013_XX_0)

(9) It definitely affects others and is annoying. (HKG_SMK_011_B1_2)

(10) In addition, being exposed to older humans smoking could give these impressionable children the notion that smoking is "cool" and is a normal part of life without showing them the accompanying side effects. (SIN_SMK_121_B1_2)

The overuse of besides, in addition and moreover by some L2 writers may as well account for the infrequency of and in their essays:

(11) Therefore, part-time job seems not so important. Besides, many mentorship and exchange programmes are also offered to increase student's social or global knowledge and let them to catch up with the changing world. (HKG_PTJ_084_B1_2)

(12) Moreover, I think the most people do not like the person that smoking because it has very bad smell and dangerous for the internal organs in body. (THA_SMK_306_B1_2)

(13) In addition, all smokers would have to smoke in dedicated confined spaces so that the only people harmed by the smoke are other smokers themselves. (SIN_SMK_103_B1_2)

(14) Furthermore, the social network become larger and larger when we enter the university, so the gathering with the friends would be more frequently. (HKG_PTJ_098_B1_2)

Simple as it appears, and is actually a special device that can bring different kinds of contextual effects, which might require extra cognitive effort on readers' part. Unlike and, devices such as besides, moreover and in 
addition can mark the additive relationship in a more explicit way, thus reducing effort required. That is probably why L2 writers prefer to use them.

\subsubsection{The Enumerating, Resultive and Summative DCs}

Another important finding is the impressive overuse of the enumerating, resultive and summative DCs by Hong Kong students. The total frequencies of the enumerating, resultive and summative DCs in HGN_B1_2, SIN_B1_2, THA_B1_2 and ENS1 are respectively 470,305, 405 and 304, indicating that the Hong Kong students have a stronger tendency to rely on the DCs of the three categories than Thai students who in turn use these devices much more than do L1 and Singaporean students. Example (15) and (16) contrast the use of these DCs by Hong Kong and L1 students:

(15) I do not agree the following statement which is that Smoking should be completely banned at all restaurants. Also, 1 would like to give some reasons to support my point. First, banning smoking at all restaurants can move smoking elsewhere. ... Second, businesses affected by smoking bans have filed lawsuits claiming that bans are unconstitutional or otherwise illegal. ... Third, it is a complete infringement on the peoples' constitutional rights because smokers have their own right to do anything in everywhere. ... Fourth, banning smoking at all restaurant will decrease the revenue of restaurants because that motion will decrease the number of smokers to go to restaurant, which is non-smoking place. Smokers may not find somewhere that can eat and smoke. All in all, banning smoking is not suitable to all restaurants and may bring trouble to restaurants' owner, smoker and non-smokers. (HKG_SMK_050_B1_2)

(16) It would be a great idea to ban smoking at Japanese restaurants. I think this for three reasons. First of all, smoking is extremely dangerous for the health of everyone around it. As a result, I do not think it is fair for the habit of a few to affect the health of many. Also, smoking can negatively affect the experience one might have had a restaurant. One enormous part of any gourmet experience is a variety of smells one can enjoy in addition to the taste of the food, and cigarette smoke absolutely destroys this part of the experience. Next, smoking is a very expensive habit, and smokers may spend hundreds or even thousands of dollars every year is to buy cigarettes. I think this money could be spent much more well and some other way, and it would be an interesting experiment for any smoker to save all the money they would have spent on smokes for an entire year and then see how much they had accumulated. My guess is that it would probably be enough for a vacation or something else similarly large. Last, smoking can damage the actual interior of a restaurant, as smoke is very bad four walls, upholstery, and floors. Therefore, smoking should be banned at restaurants. (ENS_SMK_036_XX_0)

While the L2 writer in (17) used "First $\rightarrow$ Second $\rightarrow$ Third $\rightarrow$ Forth $\rightarrow$ All in all" to link different parts of the structure, the L1 writer used "First of all $\rightarrow$ Next $\rightarrow$ Last $\rightarrow$ Therefore" to frame his argumentation. Below is another example that shows how Hong Kong students enjoy using similar enumerating and summative DCs "First $\rightarrow$ Second $\rightarrow$ Third $\rightarrow$ In conclusion" to make their discourse more cohesive and easy for readers to follow:

(17) There are three main reasons. First, university study is already our last 3 years of studies in the whole life. We should study well and at the same time joining different activities. It is time-consuming for us to have a part-time job. Second, job experiences can be earned after we have finished the university studies. There are much of times left after the end of our studies. Third, it is not necessary. Between scholarships and the support from parents, students should have enough cash to live on without having a part time job to earn extra money. In conclusion, I think that we should treasure the remaining time of studies and the chances for us to make new friends. Therefore, i don't agree that it is important for university students to have a part-time job. (HKG_PTJ_003_B1_2)

\subsubsection{The Adversative and Resultive DCs}

When using the adversative, causal or resultives DCs, it seems that L1 and Thai students are more informal than Hong Kong and Singaporean students. For instance, the more formal adversative connective however occurs only 48 times whereas its informal equivalent but occurs 178 times in L1 writers' essays. In sharp contrast, but occurs only 49 times whereas however occurs 129 times in essays written by Singaporean students. The more formal form nevertheless only occurs relatively frequent in Singaporean students' essays:

(18) Nevertheless, if a student is able to manage his time well for his different priorities, then there is no harm for the student to take up a part-time job. (SIN_PTJ_138_B1_2)

The same trend is observed in the use of the resultive so and therefore, where the informal so is used 149 times whereas the formal therefore 40 times. By contrast, so occurs only 98 times and however occurs 109 times in Hong Kong students' essays. The Hong Kong and in particular Singaporean students even use the more formal 
form hence frequently as demonstrated in (19), whereas it does not occur in L1 and Thai students' essays.

(19) Hence, by banning smoking at restaurants can help stop "promoting smoking" in public places. (SIN_SMK_131_B1_2)

The observation that Hong Kong and Singaporean students are more formal in tone when using some DCs may be attributed to L2 instruction in which learners are instructed to be more formal and therefore more academic when writing argumentative essays.

\subsubsection{The Causal DCs}

The most frequently used causal device is because which is overwhelmingly frequent in Thai students' essays. It actually ranks No. 1 in the list of top ten most frequent DCs used by Thai students (cf. Table 4). Hong Kong and Singaporean students, however, underuse this device compared to their L1 counterparts who in turn employ significantly less than Thai students. The fact that Thai students learning Chinese language also have the strong tendency to overuse Yinwei (the Chinese equivalent of because) in their Chinese essays (Ma, 2009) seems to indicate that the overuse of because by Thai students can be attributed to L1 influence.

Hong Kong students, under the influence of Chinese culture, seem to consider it unnecessary to use because to link the causal relationship between two propositions when the logic connection is strong enough, as demonstrated by (20) and (21):

(20) I agree that smoking should be completely banned at all restaurants in the country. Personally, I have a great dislike for the smell of smoke. (SIN_SMK_060_B1_2)

(21) We are university students. It is important for us to have a part-time job! (HKG_PTJ_067_B1_2)

\subsubsection{The Corroborative DCs}

Overall, the corroborative DCs are mainly used to argue against the point listed above and they can function as a polite reminder for the reader. These devices, however, are less used by both L1 and L2 writers with the Singaporean students as a slight exception.

(22) I do not see any positive about smoking actually, it wastes money as they are in fact really expensive and it does harm. (SIN_SMK_010_B1_2)

The corroborative DCs such as actually give direction to the addressee about how the upcoming utterance should be understood, highlight the relevance of the succeeding utterance as what is unexpected, and thus better prepare the addressee for the upcoming information.

\section{Conclusion}

The textual and interpersonal meanings encoded in DCs enable them particularly useful as rhetorical devices in argumentative writing. Building on previous research, this study has chosen 80 DCs under investigation, of which 23 DCs are used neither by L1 writers nor by L2 writers, indicating that both L1 and L2 university students have a limit range of DCs at their disposal. The total frequency of DCs used by Hong Kong and Singaporean students is significantly less than do L1 writers, mainly because the addictive and is by far less frequent in the two NNS groups. Hong Kong students use much more enumerating, resultive and summative DCs than both L1 writers and students from Thailand and Singapore. Thai students, on the other hand, use the causal device because much more than both L1 and other L2 writers. Hong Kong and Singaporean students are more formal in tone than L1 and Thai students when using the adversative and resultive DCs. Despite the apparent differences, there are considerable similarities of usage, with and, but, because, so, however and therefore occurring among the top 10 most frequently used devices of both L1 and L2 writers, although with strikingly different frequencies.

From the perspective of relevance theory, the proper use of DCs increases the ease with which readers follow underlying patterns. Too much use of these devices is likely to make the essays unnecessarily wordy and difficult to follow (cf. Intaraprawat \& Steffesen, 1995, p. 255). As revealed in this study, both L1 and L2 writers seem to be aware of the pragmatic function of DCs as a way to influence the interpretation of the message, and thus succeed in achieving their aims. Nevertheless, it is still not clear as to what accounts for the optimal use of DCs in argumentative writing. Future studies that go beyond learner corpus research are needed.

\section{Acknowledgements}

This study is a part of the research projects 1) "Corpus-based Contrastive Research on English Representation of Chinese Culture (13BYY019)" funded by the National Social Science Fund of China; and 2) the Project of Humanity and Social Sciences Key Research Base approved by the Ministry of Education of China 


\section{(13JJD740005).}

\section{References}

Aijmer, K. (2002). English Discourse Particles: Evidence from a Corpus. Amsterdam/Philadelphia: John Benjamins. http://dx.doi.org/10.1075/scl.10

Aijmer, K. (2013). Understanding Pragmatic Markers: A Variational Pragmatic Approach. Edinburgh: Edinburgh University Press.

Aijmer, K., \& Simon-Vandenbergen, A. M. (2006). Pragmatic Markers in Contrast. Oxford: Elsevier.

Altenberg, B. (2006). The function of adverbial connectors in second initial position in English and Swedish. In K. Aijmer, \& A. M. Simon-Vandenbergen (Eds.), Pragmatic Markers in Contrast (pp. 11-37). Oxford: Elsevier.

Andersen, E., Brizuela, M., DuPuy, B., \& Gonnerman, L. (1999). Cross-linguistic evidence for the acquisition of discourse markers as register variables. Journal of Pragmatics, 10, 339-351. http://dx.doi.org/10.1016/ S0378-2166(98)00108-8

Andersen, G. (2001). Pragmatic Markers and Sociolinguistic Variation: A Relevance-Theoretic Approach to the Language of Adolescents. Amsterdam/Philadelphia: John Benjamins. http://dx.doi.org/10.1016/s03782166(98)00108-8

Barton, E. L. (1995). Contrastive and non-contrastive connectives. Metadiscourse functions in argumentation. Written Communication, 12, 219-239. http://dx.doi.org/10.1177/0741088395012002003

Biber, D., Johansson, S., Leech, G., Conrad, S., \& Finegan, E. (1999). Longman grammar of spoken and written English. London: Longman.

Blakemore, D. (1987). Semantic Constraints on Relevance. Oxford: Blackwell.

Blackmore, D. (1992). Understanding Utterances. Oxford: Blackwell.

Blakemore, D. (2002). Relevance and Meaning: The Semantics and Pragmatics of Discourse Markers. New York: Cambridge University Press. http://dx.doi.org/10.1017/CBO9780511486456

Brinton, L. J. (1996). Pragmatic Markers in English. Grammaticalization and Discourse Functions. Berlin: Mouton de Gruyter. http://dx.doi.org/10.1515/9783110907582

Camiciottoli, B. C. (2010). Discourse connectives in genres of financial disclosure: Earnings presentations vs. earnings releases. Journal of Pragmatics, 42, 650-663. http://dx.doi.org/10.1016/j.pragma.2009.07.007

Chen, X. R. (2002). Using Discourse Connectives in Composition: An Investigation of Chinese Learners' Argumentative Writing. Foreign Language Teaching and Research, 5, 350-354. http://dx.doi.org/10.3969/ j.issn.1000-0429.2002.05.008

Crossley, A., \& McNamara, S. (2011). Shared features of L2 writing: Intergroup homogeneity and text classification. Journal of Second Language Writing, 20, 271-285. http://dx.doi.org/10.1016/ j.jslw.2011.05.007

Fischer, K. (2006). Chapter 1. Towards an understanding of the spectrum of approaches to discourse particles: Introduction to the volume. In K. Fischer (Ed.), Approaches to Discourse Particles. Oxford: Elsevier.

Fraser, B. (2006). Towards a theory of discourse markers. In K. Fischer (Ed.), Approaches to Discourse Particles. Amsterdam: Elsevier.

Granger, S., \& Tyson, S. (1996). Connector usage in English essay writing of native and non-native EFL speakers of English. World Englishes, 15(1), 19-29. http://dx.doi.org/10.1111/j.1467-971X.1996.tb00089.x

Green, C. F., Christopher, E. R., \& Jaquelin, L. K. M. (2000). The incidence and effects on coherence of marked themes in interlanguage texts: A corpus-based enquiry. English for Specific Purpose, 2, 99-113. http://dx.doi.org/ 10.1016/S0889-4906(98)00014-3

Halliday, M. A. K., \& Hason, R. (1976). Cohesion in English. London: Longman.

Hyland, K. (1998). Exploring corporate rhetoric: Metadiscourse in the CEO's letter. Journal of Business Communication, 2, 224-245. http://dx.doi.org/ 10.1177/002194369803500203

Hyland, K. (2005). Metadiscourse: Exploring Interaction in Writing. London: Continuum.

Intaraprawat, P., \& Steffensen, M. S. (1995). The use of metadiscourse in good and poor ESL essays. Journal of 
Second Language Writing, 4, 253-272. http://dx.doi.org/10.1016/1060-3743(95)90012-8

Jucker, A. H., \& Ziv, Y. (1998). Discourse markers: An introduction. In A. H. Jucker, \& Y. Ziv (Eds.), Discourse Markers. Descriptions and Theory. Amsterdam/Philadelphia: John Benjamins. http://dx.doi.org/ $10.1075 /$ pbns. 57

Liu, M. H., \& Braine, G. (2005). Cohesive features in argumentative writing produced by Chinese undergraduates. System, 33, 623-636. http://dx.doi.org/10.1016/j.system.2005.02.002

Lu, Y. J. (2012). A Study of Discourse Markers in English Argumentative Writing by English Majors: A Perspective of Relevance Theory (Unpublished master's thesis). Ganan Normal University, Ganzhou, China.

Ma, M. J. (2009). A Comparative Study of Conjunctions in Chinese and Thai Language: An Analysis into the Misuse of Chinese Conjunctions made by Thailand students (Unpublished master's thesis). Southwest University, Chongqing, China. http://dx.doi.org/10.7666/d.y1459880

Redeker, G. (1991). Review article: Linguistic markers of discourse structure. Linguistics, 29, 1139-1172. http://dx.doi.org/10.1515/ling.1991.29.6.1139

Schiffrin, D. (1987). Discourse Markers. Cambridge: Cambridge University Press. http://dx.doi.org/10.1017/ CBO9780511611841

Schourup, L. (1999). Discourse Markers. Lingua, 107, 227-265. http://dx.doi.org/10.1016/S0024-3841 (96)90026-1

Schourup, L. (2011). The discourse marker now: A relevance-theoretic approach. Journal of Pragmatics, 43(8), 2120-2129. http://dx.doi.org/10.1016/j.pragma.2011.01.005

Scott, M. (2008). WordSmith Tools 5.0. Liverpool: Lexical Analysis Software.

Sperber, D., \& Wilson, D. (1995). Relevance: Communication and Cognition. Oxford: Blackwell Publishers.

Van Dijk, T. A. (1979). Pragmatic connectives. Journal of Pragmatics, 3, 447-456. http://dx.doi.org/10.1016/ 0378-2166(79)90019-5

Wei, M. (2011). Investigating the oral proficiency of English learners in China: A comparative study of the use of pragmatic markers. Journal of Pragmatics, 43, 3455-3472. http://dx.doi.org/10.1016/j.pragma.2011.07.014

Yang, W. X., \& Sun, Y. (2012). The use of cohesive devices in argumentative writing by Chinese EFL learners at different proficiency levels. Linguistics and Education, 23(1), 31-48. http://dx.doi.org/0.1016/ j.linged.2011.09.004

Zufferey, S., Mak, W., Degend, L., \& Sanders, T. (2015). Advanced learners' comprehension of discourse connectives: The role of L1 transfer across on-line and off-line tasks. Second Language Research, 1-23. http://dx.doi.org/10.1177/0267658315573349

\section{Copyrights}

Copyright for this article is retained by the author(s), with first publication rights granted to the journal.

This is an open-access article distributed under the terms and conditions of the Creative Commons Attribution license (http://creativecommons.org/licenses/by/3.0/). 